\title{
40 Model: How to Apply Guidelines for COPD in Primary Care
}

\begin{abstract}
According to Italian General Practitioners (GPs), it is difficult to use guidelines and consensus, because they refer mainly to the disease and they are not close to the variability of real life. To help GPs perform clinical audits and address some management problems, we have devised a new analysis methodology: four-quadrant (4Q) diagnostic analysis.

$4 Q$ model describes, in a fairly realistic way, the characteristics and clinical issues of patients with chronic obstructive pulmonary disease (COPD) during visits in the General Medicine setting. Using this model, GPs can identify and group patients in four specific areas; depending on the membership, the intervention is defined by the guidelines and the evidence-based medicine.

Keywords: Management; General Practitioners; Guidelines; Four-Quadrant Model Modello a 4 quadranti: come applicare le linee guida per la BPCO nell'ambito delle cure primarie

CMI 2018; 12(1): 23-29

https://doi.org/10.7175/cmi.v12i1.1335
\end{abstract}

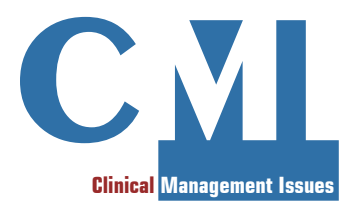

Clinical Management
GPs, "Health Search" researchers

\section{INTRODUCTION}

The statistic-epidemiologic evaluation of the activity of Italian general practitioners (GPs) through databases, such as "Health Search", shows some errors in management and clinical methodology applied to chronic diseases [1]. They are often underdiagnosed, poorly followed up, or not properly treated. For example, the prevalence of chronic obstructive pulmonary disease (COPD) seems to be slightly above $3 \%$, while the prevalence estimate in the literature is about 6\% [2]. The diagnosis of COPD is made by means of spirometry just in $49 \%$ of patients. Therapy prescriptions are inappropriate in more than half of the patients.

Italian GPs practice predominantly a "waiting medicine" rather than an "onthe-job" medicine, mainly because they are overburdened by a heavy bureaucratic routine. Therefore, they pay less attention to prevention or early diagnosis, underuse "gold standard" investigations, and finally they pay poor attention in recording data in the database, especially about comorbid chronic patients, who, due to the absence of a proper methodology in General Medicine (that should be inspired to guidelines and evidence-based medicine, but also match to personalized medicine), too often receive prescriptions of drugs as if they were affected just by one illness, receive only specialist prescriptions, or symptoms that may lead to an early diagnosis are underestimated.

A specific training of general practitioners is necessary in order to teach how to use a spirometer and correctly interpret results. Even though care of COPD patients is first of all in charge of general practitioners, optimal management should necessarily include pulmonologists, who have to make an accurate lung function evaluation (spirometry with reversibility and plethysmography, diffusion of $\mathrm{CO}$ when necessary) and supervision of treatment. In fact, COPD
Corresponding author Carla Bruschelli, MD Specialist in Internal Medicine GP, Roma

"Health Search" Researcher carla.bruschelli@gmail.com

Received: 25 October 2017 Accepted: 6 February 2018 Published: 12 April 2018 
is a preventable disease and the early diagnosis implies a mandatory multidisciplinary commitment.

\section{COPD: EPIDEMIOLOGY AND TREATMENT}

COPD is among the most widespread chronic respiratory diseases in the world [3]. It is expected to be the third cause of death in the world by 2030 [4-6]. It is preventable, but not curable and is characterized by irreversible airflow obstruction [7-9]. Bronchi (chronic bronchitis), bronchioles (small airways), and pulmonary parenchyma (emphysema) are involved. It is induced by inhalation of harmful subtle particles, especially from tobacco smoke (also passive smoke), and its main symptoms are chronic productive cough, especially in the morning and/or dyspnea, initially just after strain, and lately even at rest. It is often associated with comorbidities and requires the elimination of the main risk factors and adequate and prolonged cure over time (pharmacological and non-pharmacological, according to severity), otherwise it evolves in stages of greater severity. In fact, it is crucial to remove risk factors, especially tobacco smoke $[10,11]$.

The diagnosis is based on the presence of respiratory symptoms and/or exposure to risk factors and, in particular, on the detection of obstruction through the gold standard examination, i.e. spirometry. However, the criteria for diagnosis and treatment should always take into account the reported symptoms and the patients' quality of life [12].

Pharmacologic therapy for COPD is used to reduce symptoms, frequency and severity of exacerbations [13]. GOLD guidelines 2017 give some recommendations concerning the drug classes used in COPD setting [13]:

- Bronchodilators: They are most often given on a regular basis to prevent or reduce symptoms. They include short-acting (SABAs) and long-acting (LABAs) $\beta_{2}$-agonists;

- Antimuscarinic drugs: They provided small benefits over short-acting $\beta_{2}$-agonist in terms of lung function, health status, and requirement for oral steroids. They include short-acting (SAMAs) and long-acting antimuscarinic antagonists (LAMAs);

- Combination bronchodilator therapy: Combining bronchodilators with differ- ent mechanisms and durations of action may increase the degree of bronchodilation with a lower risk of side effects compared to increasing the dose of a single bronchodilator;

- Inhaled corticosteroids (ICSs) in combination with long-acting bronchodilator therapy: In patients with moderate to very severe COPD and exacerbations, an ICS combined with a LABA is more effective than either component alone in improving lung function, health status, and reducing exacerbations;

- Other pharmacologic treatments: antibiotics. More recent studies have shown that regular use of macrolide antibiotics may reduce exacerbation rate;

- Mucolytic (mucokinetics, mucoregulators) and antioxidant agents ( $\mathrm{N}$-acetylcysteine, carbocysteine): In COPD patients not receiving inhaled corticosteroids, regular treatment with mucolytics such as carbocysteine and $\mathrm{N}$-acetylcysteine may reduce exacerbations and modestly improve health status.

Influenza vaccination is strongly recommended. The benefits of anti-pneumococcal vaccination are well known too $[14,15]$.

The long-term administration of oxygen ( $>15$ hours per day) in patients with chronic respiratory failure has been shown to increase survival in patients with severe resting hypoxemia. Long-term oxygen therapy is indicated in patients who, in stable phase, at rest, and with the best treatment possible, in repeated hemogasanalyses over time (at least fifteen days apart from each other), have: - $\mathrm{PaO}_{2}<55 \mathrm{mmHg}\left(\mathrm{SaO}_{2}<88 \%\right)$;

- $\mathrm{PaO}_{2}$ between 56 and $59 \mathrm{mmHg}$, $\left(\mathrm{SaO}_{2}<89 \%\right)$, in the presence of pulmonary arterial hypertension, pulmonary heart, peripheral edema, hematocrit $>55 \%$.

Rehabilitation is indicated in patients with limitations in activities of daily living and should be integrated in personalized treatment.

Exacerbation is an acute modification of the usual symptoms (dyspnea, cough, and expectoration), and requires therapeutic adaptation. The differential diagnosis between disease exacerbation and worsening of symptoms is up to GPs [16]. The pharmacological treatment at home involves the administration of the same drugs used during the stable phase but with different doses, frequency, and route of administration. Other drugs, 
such as antibiotics or systemic steroids, can be added. Firstly, short-acting bronchodilators are added. Obviously, for patients who do not respond to home treatment, hospitalization should be considered.

\section{ITALIAN GPS' ROLE AND CHRONICITY MANAGEMENT}

COPD management has its main reference in the general practitioner and in the new territorial organizations of GPs [17]. GPs play a unique role in the COPD cure, from the prevention to the treatment of the most advanced phases. They consider features such as evolutionary epidemiological impact, chronicity, comorbidities, need for continuous treatments and for training sessions. This complete evaluation is more achievable if performed in territorial structures that make use of logistical and multidisciplinary assistance. As $80 \%$ of patients refer to their general practitioner at least once a year, the role of GP is crucial to early identify patients with greater probability of developing COPD, making use of anamnestic-diagnostic-therapeutic methodology of an exclusive management model providing for long-term care and problemoriented electronic medical records. Obviously, rapid and effective collaboration and communication between GPs and specialists are important aspects for the success of care path, thus it is essential to share the assistance goals and the strategies to reach them.

By examining electronic medical records of Italian GPs in the "Health Search" database (which associates individual problems/ pathologies with their specific diagnosis and therapy), situations peculiar to General Medicine may be observed, such as:

- Absence of problems/pathologies;

- Presence of symptoms associated with a problem/pathology, but without diagnosis;

- Absence of symptoms and diagnosis;

- Presence of pharmacological treatments, but without specific diagnosis;

- Presence of specific diagnostic tests, but without diagnostic conclusions; and

- Presence of diagnosis, but without proper therapies.

Since a method to approach the complexity of chronicity has not yet been developed, GPs face uncertainty, improvisation, and troubles in using a chronic illness management system. Physicians are neither prepared

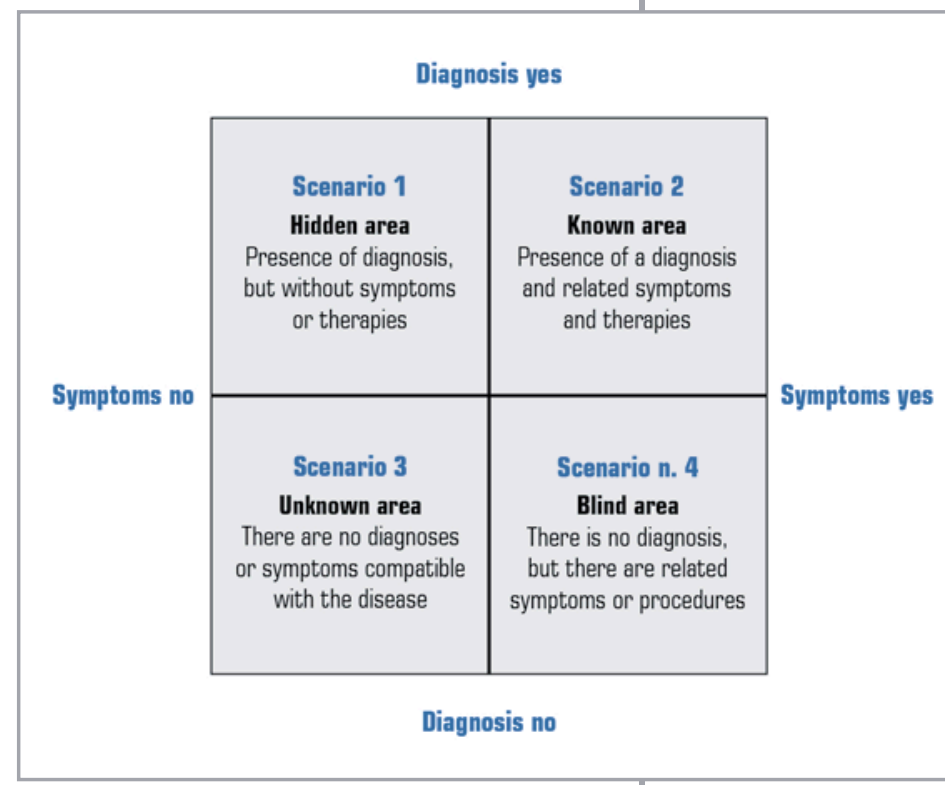

nor helped from legislative, organizational, and financial point of view. Moreover, guidelines and consensus documents have always found obstacles in General Medicine settings. In fact, they are produced considering the disease rather than the ill, and therefore they are unlikely to fit real life.

Due to the increase in the number of people affected by chronic illnesses [18], it is critical to produce valuable tools that can help GPs make prevention and early diagnosis, detect errors and/or deficiencies in the use of diagnostics, establish the staging and prescribe proper personalized therapies, but based on the criteria set out in guidelines and rules of good clinical practice. In order to act rationally, GPs must know the available choices and the consequences that may arise from each one of them.

In order to encourage GPs to the clinical and organizational audit and help them deal with profession-related management issues, we developed a new analysis methodology defined "four-quadrant (4Q) diagnostic analysis".

The "Johari window" [19], a methodology designed by Joseph Luft and Harry Ingham to study aspects of interpersonal communication (known and unknown) and Ken Wilber's "Four-quadrant patterns" were adapted to the setting of General Medicine. We have thus produced a tool that enables GPs to analyze their activity and identify, with maximum sensitivity and specificity, patients' care needs $[20,21]$.

$4 \mathrm{Q}$ analysis $[20,21]$ makes use of a scheme made by a square, divided into 4 quadrants (Figure 1), where the presence of pathology-
Figure 1.

Four-quadrant $(4 Q)$ diagnostic analysis. 


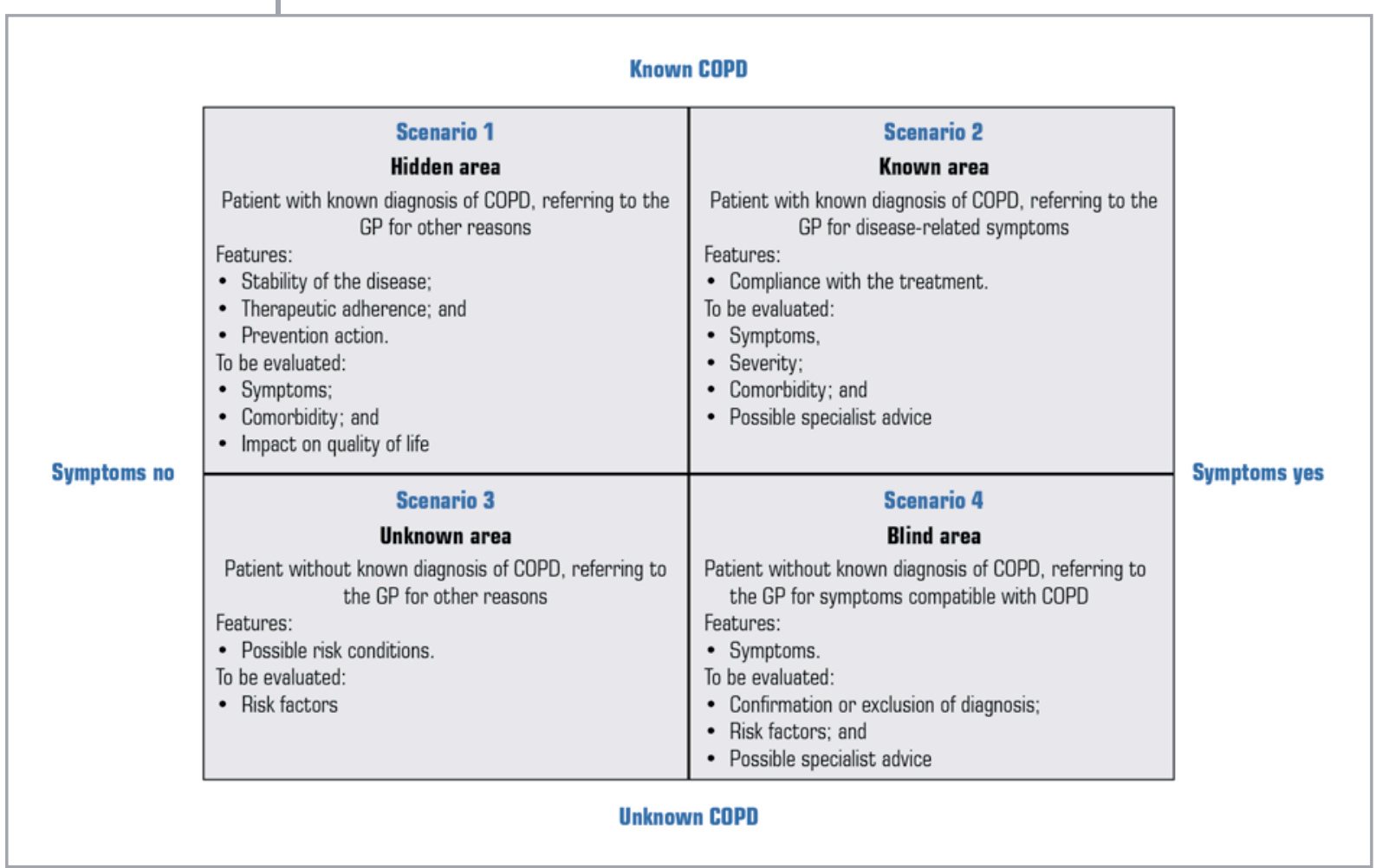

Figure 2.

Four-quadrant (4Q) diagnostic analysis applied to $C O P D$. related symptoms or procedures are evaluated (horizontal) and the presence or absence of diagnosis is highlighted (vertical).

Using this model, patients can be identified and grouped into four specific areas. Subsequently, targeted interventions can be defined, according to guidelines and evidencebased medicine. Therefore, GPs are enabled to optimize each choice between various alternatives, assessing motivations, pros, cons, and actual feasibility. In this way, in clinical practice, some factors are improved:

- The diagnostic confirmation through the expected "gold standard";

- The identification of patients with disease by expected but not performed diagnostics;

- The diagnostic investigation in symptomatic patients; and

- The identification of at-risk patients.

In organized territorial facilities of GPs, some tasks may also be carried out by other professionals, experiences colleagues, or young doctors in specific training.

\section{$4 Q$ MODEL AND COPD}

Four-quadrant diagnostic analysis may be applied to COPD [13], resulting in 4 quadrants shown in Figure 2 and described below.

\section{Hidden Area - Patient With Known Diagnosis of COPD, Referring to the GP for Other Reasons}

In this case, it is not necessary to perform a specific visit on COPD. GP should check if the spirometry which confirmed the diagnosis is recorded. Defining FEV1 as forced expiratory volume in the $1^{\text {st }} \mathrm{sec}^{-}$ ond and FVC as forced vital capacity, the threshold FEV1/FVC $<0.70$ after bronchodilators in spirometry test highlights a low airflow. If spirometry test is absent or if just a spirometry without reversibility test was performed, the COPD diagnostic pathway is re-evaluated. If suspicion is confirmed, spirometry is required.

If the diagnosis is already confirmed by spirometry, the possible decrease in respiratory function may be evaluated. GPs with proper training can perform a simple spirometry in their office (office spirometry). If the patient is a smoker, in the office, physicians or trained professionals perform a brief counseling or the 5A evidence-based approach [22]. It comes of a minimal smoking cessation intervention recommended by the major guidelines, lasting a few minutes and including 5 actions: ask, advise, assess, assist, and arrange.

If the patient follows a pharmacological therapy, some factors should be evaluated: therapeutic adherence (number of prescrip- 
tions in the medical records), correct use of the devices (demonstration), therapeutic inertia, and presence of side effects or adverse events. The need for rehabilitation is also assessed. Even if the patient does not report it spontaneously, the physician investigates on the presence of symptoms directly related to the disease, and then the effectiveness of the therapy and any comorbidities including, above all, cardiovascular pathologies and the psychological status. If the patient is in a follow-up program, regular adherence should be checked.

\section{Known Area - Patient With Known Diagnosis of COPD, Referring to the GP for Disease-Related Symptoms}

GP should always check if the spirometry which confirmed the diagnosis is recorded. The first intervention consists in distinguishing whether it comes of an episode of exacerbation of COPD or if the overall clinical picture evolved. The symptoms to be evaluated are: dyspnea, cough, and expectoration. The focus is on the timing and the speed of the symptoms appearance: quicker in case of exacerbation, slower if the clinical picture evolved. A comprehensive assessment of symptoms is recommended using measures such as the COPD Assessment Test (CAT).

The severity of the disease should be evaluated according to GOLD classification [13] (Table I).

The next step consists in deciding if the patient's conditions allow to perform homebased management or require hospitalization or specialist visit. Among factors that should be considered, there are general conditions, age, comorbidity, the number of previous exacerbations, ongoing therapy, social and family conditions. Patient's physical examination is essential, and should be completed by pulse oximetry (Emergency Room access is required when $\mathrm{SaO}_{2}<92 \%$ ). If possible, simple spirometry can be performed. Possible reasons of worsening, including poor adherence to treatment and lack of vaccinations should also be investigated. If the patient is a smoker, short counseling or $5 \mathrm{~A}$ evidencebased approach is followed. The need for rehabilitation should also be assessed.

\section{Unknown Area - Patient Without Known Diagnosis of COPD, Referring to the GP for Other Reasons}

Risk indicators should be evaluated: smoking habit (pack years), symptoms

\begin{tabular}{|c|c|c|}
\hline GOLD classification & \multicolumn{2}{|c|}{ Severity } \\
\hline GOLD 1 & Mild & FEV1 $\geq 80 \%$ predicted \\
GOLD 2 & Moderate & $50 \% \leq$ FEV1 $<80 \%$ predicted \\
GOLD 3 & Severe & $30 \% \leq$ FEV1 $<50 \%$ predicted \\
GOLD 4 & Very severe & FEV1 < 30\% predicted \\
\hline
\end{tabular}

(cough with or without expectoration, dyspnea), age > 40 years, job, outdoor and indoor pollution.

If all the indicators are negative, the GP's job ends. If only tobacco smoke is present, the GP performs a brief counseling or the $5 \mathrm{~A}$ evidence-based approach, recording the need for a follow-up visit after a short time. If positive for smoking, smoking or cough, or smoking and age, the GP prescribes a simple spirometry (office spirometry, if possible). If the patient has only respiratory symptoms, he/she should be visited and the cause will be specifically investigated.

\section{Blind Area - Patient Without Known Diagnosis of COPD, Referring to the GP for Symptoms Compatible With COPD}

The first step consists in collecting the history of: smoking habit (pack years), age, duration and type of symptoms. In any case, even though not so helpful in COPD, the physical examination must be done. In case of long-standing symptoms, smoking habit, and age $>40$ years, simple spirometry should be prescribed or performed. In case of altered results, the patient is referred to a specialist visit. In case of recent-onset symptoms, other possible causes will be evaluated through specific tests. If tobacco smoke is present, the GP performs a brief counseling or the $5 \mathrm{~A}$ evidence-based approach.

\section{CONCLUSIONS}

The success in the care of patients affected by COPD requires organizational models suitable for the General Medicine setting. The management of major chronic diseases, such as COPD, must count upon a territorial organization with complex multiprofessional Primary Care facilities, in order to optimize human and economic resources. In the current scenario, the importance of the $1^{\text {st }}$-level clinical and instrumental control made by GPs is growing.
Table I. GOLD 2017. Applicable to patients with FEV1/ $F V C<0.70$. Modified from [13]. classification of $C O P D$ 
Specific governance methodologies should be applied. An effective treatment plan for patients affected by COPD includes the application of methodology and organizational analyses models suitable for the General Medicine setting, allowing a global assessment of the individual patient and the application of diagnostics, treatments, and follow-up, as recommended by the best guidelines, but at the same time customized for each patient.
The 4Q model describes, in a fairly realistic way, the characteristics and clinical issues of patients with COPD during visits in the General Medicine setting, even though it still does not properly assess comorbidities or the impact of organizational levels of physicians. However, the application of this method can help GPs to use an audit process, to enhance "initiative medicine", apply best practice rules, and prepare a new vocational guidance aimed at "pay for performance".

Key Points

- Chronic obstructive pulmonary disease (COPD) is a widespread chronic respiratory disease

- Even though specialists' visits are required, everyday management of COPD is up to general practitioners (GPs)

- However, GPs are overburdened by a heavy bureaucratic routine

- Therefore, it is critical to produce valuable tools that can help GPs make prevention and early diagnosis, detect errors and/or deficiencies in the use of diagnostics, establish the staging and prescribe proper personalized therapies, but based on the criteria set out in guidelines and rules of good clinical practice

- The four-quadrant diagnostic analysis proposed by the authors aims at helping GPs in the management and identification of patients affected by COPD by grouping patients in 4 areas:

- Hidden area - patient with known diagnosis of COPD, referring to the GP for other reasons

- Known area - patient with known diagnosis of COPD, referring to the GP for disease-related symptoms

- Unknown area - patient without known diagnosis of COPD, referring to the GP for other reasons

- Blind area - patient without known diagnosis of COPD, referring to the GP for symptoms compatible with COPD

\section{Funding}

This article has been published without the support of sponsors.

Conflicts of Interests

The authors declare they have no competing financial interests concerning the topics of this article.

\section{BIBLIOGRAPHY}

1. Bettini GL, Bonvicini A, Braga A, et al. BPCO a $270^{\circ}$. Rivista Società Italiana di Medicina Generale 2013: 6: 11-15

2. Buist AS, McBurnie MA, Vollmer WM, et al. BOLD Collaborative Research Group. International variation in the prevalence of COPD (the BOLD Study): a population based prevalence study. Lancet 2007; 370: 741-50; https://doi.org/10.1016/S0140-6736(07)61377-4

3. Viegi G, Pistelli F, Sherrill DL, et al. Definition, epidemiology and natural history of COPD. Eur Respir J 2007; 30: 993-1013; https://doi.org/10.1183/09031936.00082507

4. Istituto Nazionale di Statistica ISTAT. Condizioni di salute e ricorso ai servizi sanitari. Detection years 1994-2013. Edition February, 9, 2016; Available at https://www.istat.it/it/archivio/5471 (last accessed April 2018)

5. AA.VV. Broncopneumopatia cronica ostruttiva e comorbidità croniche. Italian Journal of Medicine 2011; 5 (Suppl. 1) 
6. Rossi FF, Pedone C, Antonelli Incalzi R. Broncopneumopatia cronica ostruttiva e patologie cardiovascolari: ruolo dell'infiammazione sistemica. Recenti Prog Med 2011; 102: 109-13

7. World Health Organization. Global surveillance, prevention and control of chronic respiratory diseases. A comprehensive approach. WHO report 2007. Available at http://www.who.int/gard/ publications/GARD_Manual/en/ (last accessed March 2018)

8. Gibson GJ, Loddenkemper R, Lundbäck B, et al. Respiratory health and disease in Europe: the new European Lung White Book. Eur Respir J 2013; 42: 559-63. https://doi. org/10.1183/09031936.00105513

9. Hogg JC, Chu F, Utokaparch S, et al. The nature of small-airway obstruction in chronic obstructive pulmonary disease. N Eng J Med 2004; 350: 2645-53; https://doi.org/10.1056/ NEJMoa032158

10. De Marco R, Accordini S, Cerveri I, et al.; European Community Respiratory Health Survey Study Group. An international survey of chronic obstructive pulmonary disease in young adults according to GOLD stages. Thorax 2004; 59: 120-5; https://doi.org/10.1136/ thorax.2003.011163

11. Ministero della Salute. Piano sanitario nazionale 2011-2013; B.3 Malattie respiratorie croniche: p. 102. November, 5, 2010; Available at http://www.ipasvi.it/archivio_news/pagine/28/ PIANO\%20SANITARIO\%20NAZIONALE.pdf (last accessed April 2018)

12. Baraldi E, Bevilacqua M, Bruschelli C, et al.; Gruppo di Lavoro GARD-Italy "Sorveglianza malattie respiratorie”. Sorveglianza nell'ambito delle patologie respiratorie. July,25, 2015. Available at http://www.salute.gov.it/imgs/C_17_pubblicazioni_2386_allegato.pdf (last accessed April 2018)

13. Global Initiative for Chronic Obstructive Lung Disease. Global strategy for the diagnosis, management and prevention of chronic obstructive pulmonary disease. Available at http:// goldcopd.org/gold-2017-global-strategy-diagnosis-management-prevention-copd/ (last accessed March 2018)

14. Siafakas NM, Vermeire P, Pride NB, et al. Optimal assessment and management of chronic obstructive pulmonary disease. ERS, consensus statement. Eur Respir J 1995; 8: 1398-420; https://doi.org/10.1183/09031936.95.08081398

15. National Clinical Guideline Centre. Chronic obstructive pulmonary disease: management of chronic obstructive pulmonary disease in adults in primary and secondary care. London: National Clinical Guideline Centre, 2010. Available at http://guidance.nice.org.uk/CG101/ Guidance/pdf/English (last accessed March 2018)

16. AIMAR, AIPO, SIMER, et al. La gestione clinica integrata della BPCO. October, 2013. Available at https://www.simg.it/documenti/aree_cliniche/Pneumologica/supporti/gestione_ bpco/Gestione\%20BPCO.pdf (last accessed April 2018)

17. Bettoncelli G, Blasi F, Brusasco V, et al. The clinical and integrated management of COPD. Sarcoidosis Vasc Diffuse Lung Dis 2014; 31 Suppl 1: 3-21

18. Istituto Nazionale di Statistica (ISTAT). May, 4, 2017. Anni 2003-2014. L'evoluzione della mortalità per causa: le prime 25 cause di morte. Available at http://www.istat.it/it/files/2017/05/ Report-cause-di-morte-2003-14.pdf (last accessed April 2018)

19. Luft J. Introduction à la dynamique des groups. Toulouse: Éd. Privat, 1968

20. Bettoncelli G, Monti GC,Paolini I. Analisi 4Q. Analisi diagnostica a quattro quadranti. Rivista Società Italiana di Medicina Generale 2009: 3: 42-43

21. Bruschelli C, Bettoncelli G, Monti GC. [Management of Adult Obstructive Sleep Apnea Syndrome in General Practice: a new model of risk prevention]. Clinical Management Issues 2017; 11: 31-7

22. Ministero della Salute, Istituto Superiore Sanità. Linee guida cliniche per promuovere la cessazione dell'abitudine al fumo. Aggiornamento 2008. Available at http://old.iss.it/binary/ fumo/cont/linee_guida_brevi_2008.pdf (last accessed April 2018) 